\title{
0 fotojornalismo gaúcho dos anos 1970: Jacqueline Joner e Eneida Serrano 1
}

\author{
El fotoperiodismo gaúcho de la década 1970: Jacqueline Jonery Eneida Serrano
}

The Rio Grande do Sul photojournalism of the 1970s: Jacqueline Joner and Eneida Serrano

Carolina Martins Etcheverry $^{*}$

\section{Resumo}

Este artigo tem por objetivos apresentar e problematizar o trabalho de duas fotojornalistas gaúchas nos anos 1970, Jacqueline Joner (1953) e Eneida Serrano (1952), a fim de compreender sua inserção e seu papel no campo fotojornalístico gaúcho. As fotógrafas fazem parte da história da fotografia brasileira, o que permite compreender não apenas as tensões nas relações de trabalho e as formas de opressão que sofreram, mas também os mecanismos de emancipação. Assim, abordam-se, de modo específico, as fotografias do fotolivro Santa soja, a passagem pelo jornal Agricultura \& Cooperativismo e pela agência de fotografia Ponto de Vista.

Palavras-chave: Feminismo. Fotografia documental. Fotojornalismo.
Este artigo tem por objetivos apresentar e problematizar a trajetória de trabalho de duas fotojornalistas gaúchas na década de 1970, quando em seu início de carreira, a fim de compreender sua inserção e seu papel no campo fotojornalístico. Jacqueline Joner e Eneida Serrano, atualmente fotógrafas bastante reconhecidas, inclusive pelo seu pioneirismo, são um exemplo de como há tensão e resistência no mercado de trabalho. Analisando suas trajetórias, que se cruzam em muitos aspectos, pretende-se perceber as formas de resistência encontradas por elas para se inserirem e se manterem no fotojornalismo, fazendo um trabalho de relevância social. Fazemos isso a partir de três etapas. A primeira procura analisar as dificuldades e os embates travados por elas, a fim de vencer a resistência masculina ao seu trabalho; a segunda analisa o trabalho na cooperativa de jornalistas Coojornal, editando a revista Agricultura $\mathcal{E}$ Cooperativismo, e a criação da agência Ponto de Vista; por último, analisam-se aspectos do

\footnotetext{
Doutora em História pela Pontifícia Universidade Católica do Rio Grande do Sul. Bolsista do Programa Nacional de Pós-Doutorado da Coordenação de Aperfeiçoamento de Pessoal de Nível Superior no Programa de Pós-Graduação em História na mesma instituição. E-mail: etchev@gmail.com
}

Recebido em 08/08/2018 - Aprovado em 19.09.2018 http://dx.doi.org/10.5335/hdtv.19n.1.9052 
fotolivro Santa soja, publicação do grupo de fotógrafos da agência, que reúne imagens sobre a agricultura e o trabalho no campo.

\section{Jacqueline Joner e Eneida Serrano: trajetórias e resistências}

A história da fotografia no Rio Grande do Sul, desde o século XIX, é contada a partir da ótica masculina, enfatizando a presença de inúmeros fotógrafos, pois a profissão está relacionada, no século XIX, ao peso do equipamento e à manipulação de produtos químicos, o que dificultaria o acesso às mulheres. No entanto, há a presença de mulheres na fotografia desde o início, muitas vezes trabalhando nos estúdios de seus pais, maridos ou filhos. ${ }^{2} \mathrm{Na}$ área de fotojornalismo das redações de jornal no século $X X$, a predominância masculina, não mais atribuída ao peso das máquinas, é justificada pela permanência de uma segregação ocupacional ainda muito baseada no gênero.

Figura 1 - Jaqueline Joner e Eneida Serrano (fotografando), final dos anos 1970

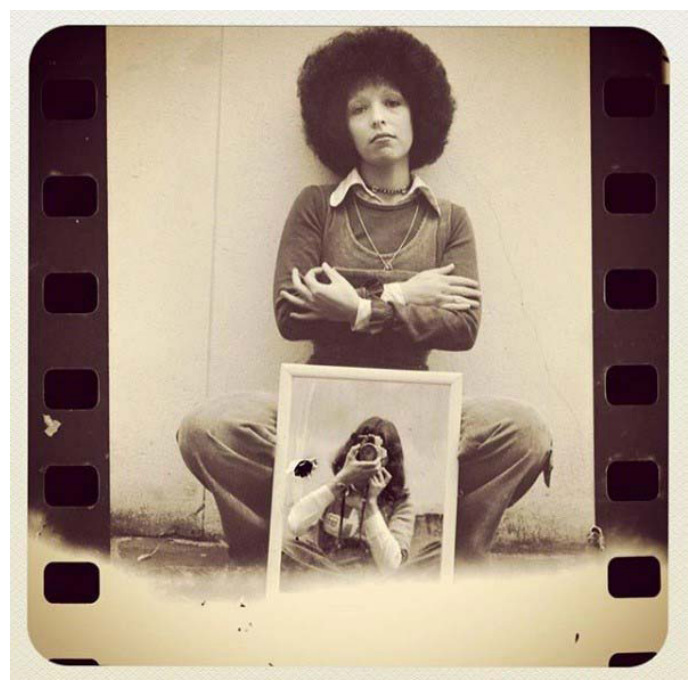

Fonte: acervo de Eneida Serrano.
Jacqueline Joner (1952) e Eneida Serrano (1953) são profissionais que apresentavam um diferencial em relação aos colegas fotógrafos da época, uma vez que tinham formação superior em Jornalismo. As duas fotógrafas fizeram estágio no jornal Zero hora, ainda hoje um dos principais veículos de comunicação do Rio Grande do Sul, em 1974 e foram demitidas mais ou menos na mesma época. ${ }^{3} \mathrm{O}$ "diferencial" universitário, segundo depoimento de ambas, não facilitou a vida nas redações. Conforme depoimento de Jacqueline Joner,

Era de três meses de repórter fotográfica na Zero Hora, eu fazia estágio, a Eneida trabalhava lá como estagiária também, foi onde nós nos conhecemos. E nós duas fomos postas para a rua ao mesmo tempo. Porque nós fazíamos parte de um grupo que era considerado revolucionário demais na época, por que nós éramos formados, ou melhor, estudantes de comunicação. Os fotógrafos da geração anterior à nossa vinham de outra escola que existia, que era a escola da época do Assis Hoffman, que trabalhava na Caldas Jr., e do Telmo Cúrcio, da Zero Hora. Estes fotógrafos vinham de uma carreira dentro do jornal, que às vezes começava até como office-boy, passava pelo laboratório e ia acontecendo. Nós íamos para lá com revistas, com livros na mão. A gente tinha um outro grau de informação (SEIDL, 2016, p. 157).

Sobre a mesma situação, Eneida Serrano afirma que "estava conhecendo uma atividade que não era uma atividade esperada para uma mulher exercer, mas era o momento em que aquilo passou a ser possível para uma mulher exercer". ${ }^{4}$ Em depoimento oral em evento na Faculdade de Comunicação da Pontifícia Universidade Católica do Rio Grande do Sul (PUCRS), Jacqueline Joner 
reiterou a dificuldade encontrada para conseguir estágio no jornal Correio do povo, ${ }^{5} \mathrm{em}$ que ouviu do diretor do jornal: "mulher não entra e não vai entrar antes de eu morrer" ${ }^{6}$

Podemos procurar compreender a dificuldade encontrada pelas fotógrafas não apenas pelo fato de que tinham formação superior e, por isso, se diferenciavam dos autodidatas, mas também pela própria forma como o trabalho feminino era entendido na época. De acordo com Danièle Kergoat (2016), o trabalho, definido como produção do viver em sociedade, é um analisador privilegiado das relações sociais de sexo e de classe. A divisão sexual do mercado de trabalho aponta o trabalho doméstico e o trabalho do cuidado como espaços de trabalho aceitos para mulheres. As relações sociais que emanam dessa forma de pensar são necessariamente de dominação, opressão e exploração, de acordo com uma perspectiva feminista materialista (KERGOAT, 2016). Segundo tal perspectiva,

[...] o social estrutura-se em torno de tensões que produzem grupos sociais [...] esses grupos sociais estão, assim, em relação de antagonismo e se constituem em torno de uma questão: as formas de divisão do trabalho (KERGOAT, 2016, p. 22).

Cria-se, assim, um sujeito político autônomo, gerador de resistências em relação à divisão de trabalho.

Especificamente sobre o trabalho feminino no Brasil, Nadya Guimarães e Murillo Brito (2016) procuram entender a mercantilização do trabalho da mulher, desde os anos 1960. Segundo gráficos apresentados pelos autores, há um aumento na taxa de participação de mulheres no mercado de trabalho na década de 1970, com um início tímido em fins dos anos 1960. De acordo com eles,

No Brasil, até o fim dos anos 1960, a maioria dos indivíduos em idade para trabalhar obtinha sua sobrevivência sem recurso à mercantilização do trabalho [...]. Mas foi apenas a partir dos anos 1980 que mais da metade daqueles em idade de trabalhar (oferta potencial) passou a se engajar no mercado de trabalho, fosse como ocupados, fosse como desempregados (oferta efetiva de trabalho) [...]. Esse movimento médio, conquanto importante, esconde uma notável característica: a mercantilização é um processo que se declina no feminino. À luz dos dados censitários brasileiros, vemos que meio século atrás o mercado de trabalho era um domínio dos homens; atualmente, deixou de ser assim. Em 1960, quase oito em cada dez homens aptos a trabalhar ali buscavam os meios de sobreviver, contra menos de duas em cada dez mulheres (GUIMARÃES; BRITO, 2016, p. 72).

Podemos entender as dificuldades encontradas por Joner e Serrano a partir dessas perspectivas, pensando no conflito específico de ser fotojornalista quando, no senso comum da época, a mulher, se fosse trabalhar, deveria escolher algo voltado à área do cuidado (enfermeira, professora, doméstica), considerada mais "apropriada" à sensibilidade feminina. As fotojornalistas agem, desse modo, como sujeitos políticos autônomos, na medida em que procuram alternativas à opressão encontrada nos veículos de comunicação mais tradicionais. Duas foram as alternativas encontradas: o trabalho cooperativado (na Coojornal) e o trabalho em agência de fotografia própria (a Ponto de Vista).

Em 1974, a partir da iniciativa de diversos jornalistas gaúchos, nascia a Cooperativa 
de Jornalistas de Porto Alegre (Coojornal). Funcionava como uma agência de conteúdo, editando diversos jornais e boletins informativos, entre eles a revista Agricultura \& Cooperativismo, de que se discute adiante. Em 1976, a cooperativa lançou seu próprio jornal, homônimo, reconhecido como um dos jornais alternativos mais importantes fora do eixo Rio-São Paulo (KUCINSKI, 1991). Sobre o trabalho na Coojornal, Eneida Serrano afirma o seguinte:

[...] na Coojornal, que tinha então o projeto do jornal propriamente dito, que era mensal e tinha pouca fotografia e uma revista que era a Agricultura \& Cooperativismo. Essa sim demandava mais trabalho e demandava que, se tinha um viajando, o outro estar aqui (sic). Aí eu fui e logo depois o Luiz Abreu também (SEIDL, 2016, p. 125).

Jacqueline Joner e Eneida Serrano, juntamente com Luiz Abreu, Genaro Joner e André Pereira, saem da Coojornal em 1979 e fundam a agência de fotografia Ponto de Vista, também com gestão cooperativa. De acordo com Jacqueline Joner,

Nós saímos da Coojornal, todos, porque nós saímos juntos, com muitos jornalistas no primeiro e grande racha que houve dentro da Coojornal. Nós todos saímos. E aí fazer o quê? Aí a ideia da sucessão, a gente pode ter menos custo dividindo o mesmo espaço, dividindo infraestrutura. Cada um tendo seus contatos, fazendo o seu trabalho, juntos [...]. Então criamos esta agência, Ponto de Vista, que foi a primeira aqui no sul, e foi uma das primeiras no país (SEIDL, 2016, 165).

Charles Monteiro e Caio Proença (2016) afirmam o seguinte sobre a emergência de agências de fotografia nos anos 1970:
[...] algumas agências fotográficas [...] floresceram no final dos anos 1970 e início de 1980 no Brasil. Elas tinham diferentes formas de organização. Algumas eram cooperativas de fotógrafos e outras tinham proprietários que se encarregavam de comercializar as imagens de vários profissionais autônomos. Tendo em vista as restrições da liberdade criativa em grandes empresas de comunicação, as agências de fotógrafos eram uma alternativa atraente para vários profissionais com experiências prévias no fotojornalismo, que buscavam uma valorização de seu trabalho, o reconhecimento da autoria das imagens e maior autonomia para criar as suas próprias pautas. Algumas agências como a F4, Ágil Fotojornalismo e a Ponto de Vista procuraram seguir os mesmos princípios de funcionamento das agências fotográficas criadas na Europa e nos EUA após a Segunda Guerra Mundial, especialmente o modelo de Magnum Photo (MONTEIRO; PROENÇA, 2016, p. 192).

A saída do veículo de grande circulação para o trabalho em uma cooperativa de jornalistas claramente oposta ao contexto da ditadura militar pode ser entendida como uma estratégia de sobrevivência das fotógrafas, aliadas a outros profissionais que não encontravam espaço para publicar suas matérias e fotografias. Da mesma forma, a criação de uma agência de fotografia pode ser interpretada como um marco da resistência não apenas do trabalho das fotógrafas, mas também da própria fotografia, nesse momento em busca de valorização. ${ }^{7}$

A seguir, para compreender um pouco melhor as fotografias documentais de Jacqueline Joner e Eneida Serrano, é preciso entender especificamente seu trabalho na revista Agricultura \& Cooperativismo, de que saíram as fotografias escolhidas para figurar 
no fotolivro Santa soja, espaço de projeção da fotografia documental e da fotografia-expressão. De acordo com André Rouillé (2009), à fotografia-documento cabem duas características que marcam sua nuance, a saber, a designação (de coisas) e a expressão (de acontecimentos). De acordo com o autor,

A uma fotografia-documento que compreende uma expressão, isto é, que engloba um acontecimento, nós chamaremos de "fotografia-expressão". A fotografia-expressão exprime o acontecimento, mas não o representa. Levaremos em consideração aqui, a hipótese segundo a qual a passagem do documento-designação para documento-expressão repercute na fotografia como um fenômeno mais global: a passagem de um mundo de substâncias, de coisas e de corpos, para um mundo de acontecimentos, de incorporais. A passagem de uma sociedade industrial para uma sociedade da informação (ROUILLÉ, 2009, p. 137).

De acordo com Monteiro e Proença (2016), as modificações no campo profissional da fotografia ocorridas a partir dos anos 1970, com a criação das editorias de fotografia e do Núcleo de Fotografia da Fundação Nacional de Artes, fizeram com que as fotografias artística e documental ganhassem importância, entrando para galerias e museus, com exposições e fotolivros. Além disso, vale destacar as duas esferas pelas quais transitam as fotografias de Joner e Serrano: a fotorreportagem e o fotodocumentarismo. De caráter mais imediatista, a fotorreportagem pode servir para cobrir as pautas cotidianas, tendo um compromisso com a realidade da notícia, enquanto o fotodocumentarismo tem enfoque em fenômenos estruturais, sendo uma narrativa que propõe determinada interpretação visual sobre um tema $(\mathrm{MON}$ -
TEIRO, 2016). Há uma diferença de tempo empregado na produção da fotografia, bem como na forma como é apresentada.

É interessante notar, no caso a seguir, a mudança de estatuto das fotografias da agência Ponto de Vista, ${ }^{8}$ que aparecem primeiramente como imagens em uma fotorreportagem (para uma revista especializada em agricultura) e acabam integrando um livro fotodocumental cuja narrativa, evidenciada pela ordem sequencial das imagens, apresenta uma ideia de vida no campo que leva a pensar em uma situação de pobreza e crise, ideia essa que não é, necessariamente, a apresentada na reportagem original que a fotografia acompanha. A potência das fotografias feitas por Jacqueline Joner e por Eneida Serrano está justamente na sua polissemia.

\section{A revista Agricultura \& Cooperativismo}

A revista Agricultura \& Cooperativismo era uma publicação mensal elaborada pela cooperativa de jornalistas Coojornal para a Federação Cooperativa de Trigo do Rio Grande do Sul (Fecotrigo), com o objetivo de trazer informações sobre agricultura, pecuária e a vida dos pequeno-agricultores. As reportagens eram acompanhadas de muitas fotografias e de entrevistas, e o trabalho era realizado por jornalistas e fotógrafos que viajavam pelo interior para cobrir as pautas estabelecidas pela redação.

Jacqueline Joner foi editora de fotografia da revista, entre outubro de 1976 (edição número 6) e março de 1978 (edição número 23), e seguiu participando como fotógrafa 
até julho de 1979 (edição 39). O papel do editor de fotografia era valorizar a fotografia em relação ao texto, definindo quais entrariam na edição e como seriam diagramadas. Como aponta Caio Proença (2017), foi um momento em que a fotografia passou a ser valorizada nas redações, alterando as estratégias de comunicação.

Eneida Serrano participou como fotógrafa das edições de junho de 1976 (edição número 2) a agosto de 1979 (edição 40) e explica da seguinte forma seu trabalho na revista:

Eu me envolvia mais, eu gostava mais do trabalho na revista [...]. Era uma revista da Fecotrigo que tinha essa publicação e o objetivo era distribuir esse veículo para todas as cooperativas do Rio Grande do Sul. Isso era muito rico, era muito legal (SEIDL, 2016, p. 126).

A atenção às pautas se reflete na grande quantidade de fotografias presentes nas matérias e nas entrevistas com os colonos. Os temas eram aqueles ligados ao campo pragas, obtenção de subsídios para plantio, vida do colono, falta de terras e de incentivo, entre outros -, e as fotografias acompanham boa parte das reportagens. Como mostram as páginas a seguir, há um predomínio dos retratos, enfatizando um caráter documental da fotografia, que é importante nas fotografias do fotolivro Santa soja.
Figura 2 - Fotografias de Eneida Serrano para Agricultura \& Cooperativismo, ano I, número 9 , janeiro de 1977

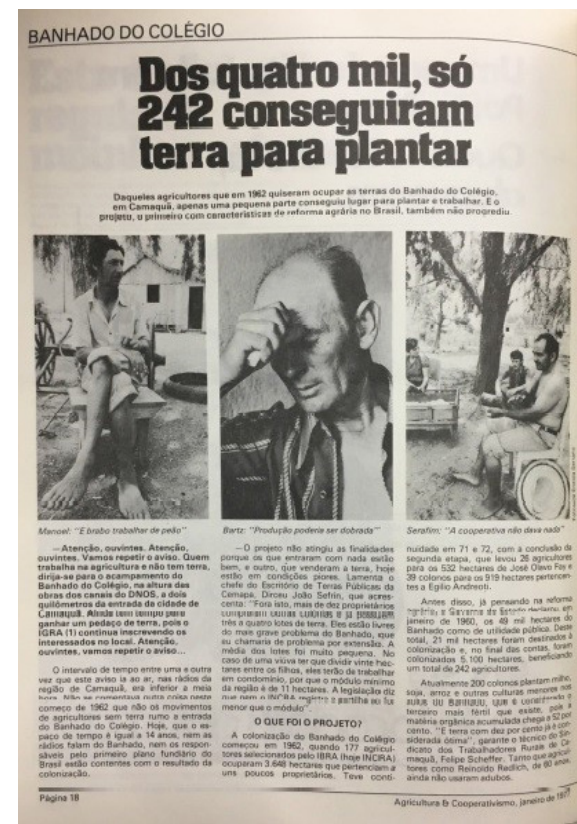

Fonte: acervo Escoop.

Figura 3 - Fotografias de Jacqueline Joner para Agricultura \& Cooperativismo, ano III, número 32, dezembro de 1978

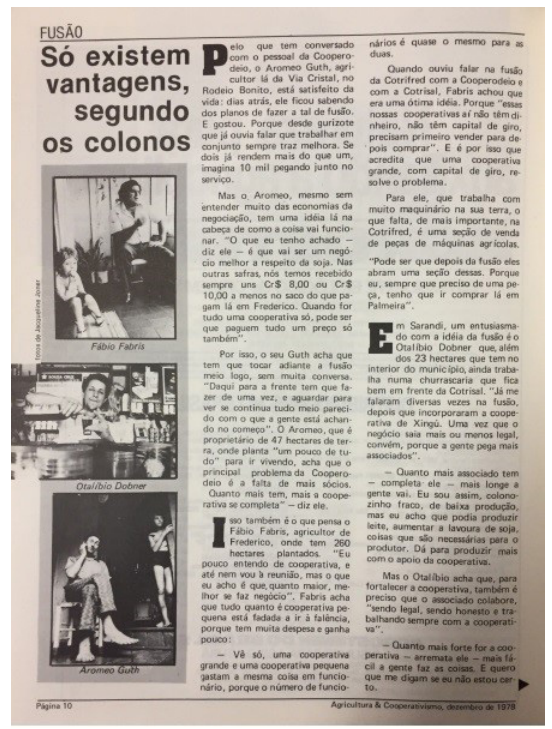

Fonte: acervo Escoop. 
Os fotógrafos envolvidos na produção de imagens para a revista e depois para o livro afirmam se tratar de um trabalho de interesse social, que acaba sendo o enfoque documental dado ao tratamento das imagens em conjunto com as reportagens. Na Figura 2, por exemplo, acompanhando o título que indica a dificuldade para se conseguir terra para plantar, a fotografia central tem ênfase dramática na pose do senhor Bartz, e o claro-escuro enfatiza a legenda em que se lê que a produção poderia ser dobrada.

As fotografias de Jacqueline Joner, por sua vez, apresentam ângulos inovadores (Figura 3), enfatizando as figuras representadas em seu cotidiano. A terceira imagem de cima para baixo, por exemplo, mostra um homem sentado no que parece ser a sala de sua casa, e uma menina em pé, está abraçada ao marco da porta. O homem conversa com os responsáveis pela reportagem (supomos), e a menina olha ao longe. Muitas fotografias eram feitas dentro das casas ou dos ambientes de trabalho dos colonos, e o modo como os fotógrafos obtinham as imagens é descrito por Jacqueline Joner do seguinte modo:

A gente não quer agricultor nenhum com uma roupa de domingo, a gente quer com a roupa de trabalho. Então todas as nossas fotos, dá para ver que eles estão na lida. Saíram da lida neste momento para fotografar [...]. Estar muito perto deles também era uma condição (SEIDL, 2016, p. 166).

O objetivo dos fotógrafos parece ter sido, juntamente com o cumprimento da pauta da revista, criar um registro da situação dos colonos em seu cotidiano, sem arrumá-los para a fotografia, evidenciando ainda mais o caráter documental das imagens. Luiz Abreu é enfático nesse ponto, ao afirmar que saíam para fazer a pauta, "mas já com a ideia de fazer uma documentação próxima deles, ao dia-a-dia [sic] deles, à realidade deles, muito bem feitas. A gente até se propunha que eles não aparecessem adomingados na foto" (SEIDL, 2016, p. 180). Essa intenção documental fica evidente no livro Santa soja.

\section{0 olhar engajado no fotolivro Santa soja}

O fotolivro Santa soja, publicado em 1979, é uma compilação de fotografias dos membros da agência Ponto de Vista, feitas principalmente durante o trabalho dos fotógrafos na revista Agricultura \& Cooperativismo, e foi publicado pela Assembleia Legislativa do Rio Grande do Sul. São ao total 70 fotografias, sendo que 21 são de Jacqueline Joner e 10, de Eneida Serrano. ${ }^{9}$ A organização do boneco do livro ficou a cargo de Joner e de Luiz Abreu, e o patrocínio da assembleia foi alcançado por intermédio da mãe de Joner, que trabalhava no local.

\section{Figura 4 - Capa do fotolivro Santa soja}

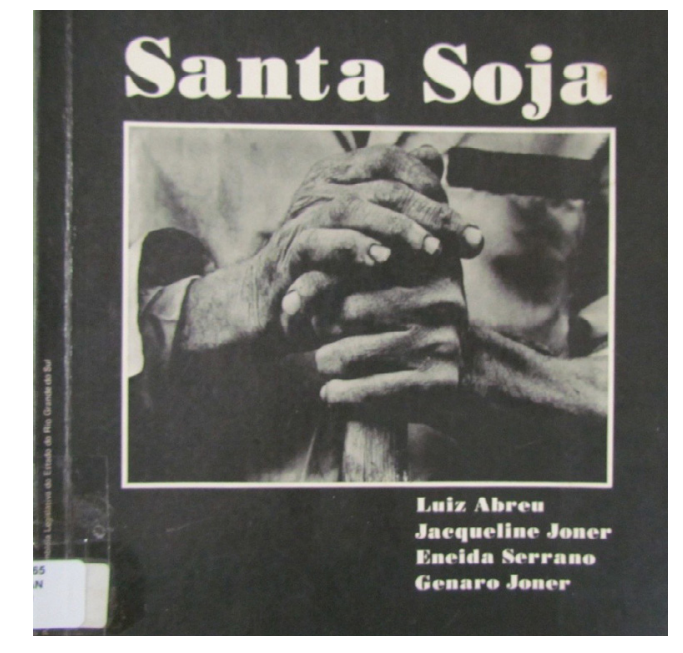

Fonte: acervo da biblioteca da Assembleia Legislativa do Rio Grande do Sul. 
Ana Maria Mauad define "olhar engajado" - conceito que utilizamos para analisar as fotografias em estudo - da seguinte forma:

[...] a noção de engajamento do olhar do fotógrafo pode ser delimitada pelas posições que os fotógrafos ocupam nos espaços sociais e pela prática propriamente fotográfica que eles vão adquirindo ao longo da sua trajetória. Por prática, no caso, entendemos o saber-fazer que se constitui de um conjunto de conhecimentos, técnicas e procedimentos acumulados pelo fotógrafo no seu aprendizado fotográfico e processados em sua vivência cultural (MAUAD, 2008, p. 36).

O fotógrafo seria, então, um mediador cultural, traduzindo em imagens suas experiências e vivências (MAUAD, 2008). Os fotógrafos responsáveis pelo fotolivro Santa soja procuraram fazer uma fotografia-denúncia, a fim de mostrar a situação de precariedade dos trabalhadores rurais do noroeste do Rio Grande do Sul (em especial, as regiões de Passo Fundo e Carazinho). Ao observar as Figuras 5 e 6, percebemos a filiação dos fotógrafos a uma fotografia humanista, evidenciando sua posição política. Erika Zerwes define tal fotografia da seguinte forma:

[...] a fotografia humanista - enquanto uma estética voltada para a fotografia documental, em preto e branco, geralmente feita com câmeras $35 \mathrm{~mm}$, e também enquanto uma ética no que se refere às temáticas universais e a certa preocupação dos fotógrafos com a "dignidade humana" como postulada no discurso de De Gaulle - chegou a impactar a história da fotografia nas regiões mais diversas do globo, inclusive na América Latina (2016, p. 318).
Se pensarmos que foram feitas em meio ao regime autoritário por que passou o Brasil, a potência dessas fotografias permite entender o próprio ato de fotografar como um ato de resistência. A escolha do tema da terra, enfatizando a vida dos pequenos proprietários rurais em face das mudanças relacionadas à política da terra, demonstra a sensibilidade desse grupo de fotógrafos.

Os agricultores foram fotografados com a família, em retratos individuais e, raras vezes, no campo trabalhando. Na Figura 5, de Jacqueline Joner, há uma mãe e seus dois filhos em ângulo que remete diretamente à fotografia da mãe migrante, de Dorothea Lange. ${ }^{10} \mathrm{~A}$ atenção do observador se volta para os olhos sofridos do trio, atentos a alguém que não podemos ver. As mãos, por sua vez, trazem consigo resignação. É uma imagem amorosa, ao mesmo tempo que remete ao sofrimento, à Pietà, à mãe preocupada que chora por seus filhos.

Eneida Serrano, na Figura 6,11 retrata um avô e seu neto, sentados diante de uma parede repleta de retratos de família. É uma casa simples, de madeira, e o mobiliário que podemos ver é igualmente simples. A riqueza da fotografia está na representação da família rural brasileira, que guarda consigo a memória de seus antepassados. A roupa do avô é típica do Rio Grande do Sul, uma pilcha, o que indica também a posição do fotografado em relação à sua identidade cultural. Serrano segue fazendo retratos íntimos de interiores de casas da serra gaúcha, que podemos ver na série intitulada Interiores. ${ }^{12}$ 
Figura 5 - Fotografia de Jacqueline Joner

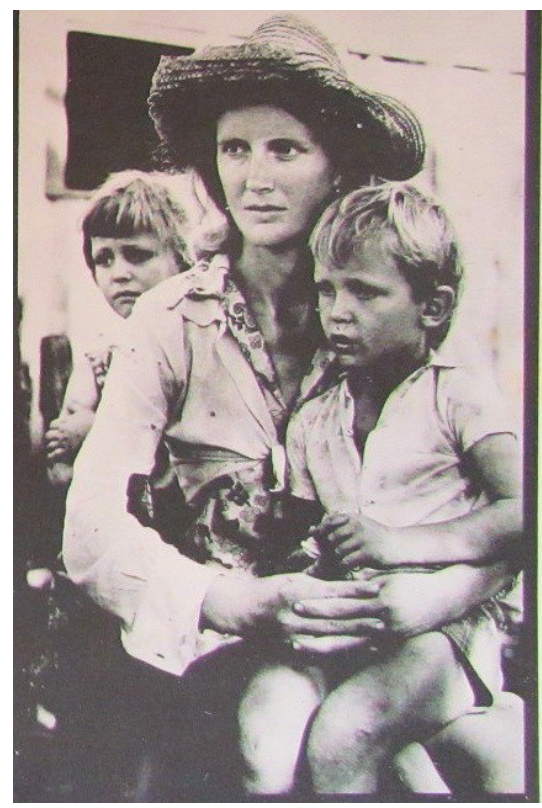

Fonte: Santa soja, de 1979.

Figura 6 - Fotografia de Eneida Serrano

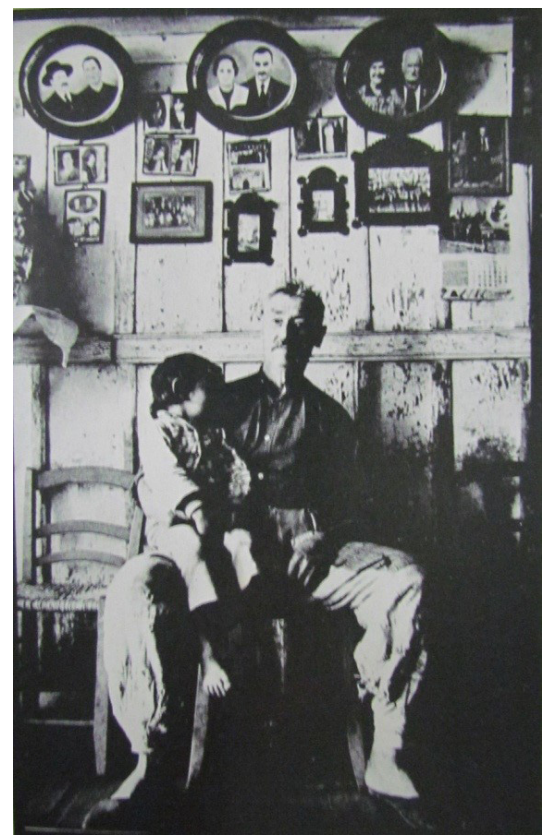

As fotografias de Joner e de Serrano são marcadas pela experiência histórica da condição de ser mulher, forjada nas suas lutas e dificuldades. É daí que vem seu olhar engajado. A prática fotográfica ${ }^{13}$ define os sujeitos, seus modos de ver e entender o mundo, produzindo um olhar a partir de padrões de intenção que geram discursos, com base em séries documentais que lhes dão sentido. As fotografias do fotolivro Santa soja são exemplo disso, na medida em que engendram discursos sobre a precariedade da vida no campo, enfatizando aspectos do cotidiano dos agricultores. A sensibilidade das fotógrafas está justamente em mostrar a vida cotidiana que segue, apesar das dificuldades.

Além dos retratos, há uma série de imagens de objetos de trabalho, como chapéus e panelas, que mostra o universo íntimo e cotidiano dos agricultores. Na Figura 7, podemos ver, em evidência, o chapéu no chão, em primeiro plano. É objeto de uso diário no trabalho no campo. $\mathrm{O}$ agricultor também usa um chapéu, mostrando que é um objeto comum na vida de quem trabalha com a terra, de quem está exposto ao sol o dia inteiro. Do mesmo modo, na Figura 8, de Eneida Serrano, observamos as louças recém lavadas no que supomos ser a cozinha da casa. O jogo de luz e sombra garante a dramaticidade da cena corriqueira e cotidiana.

Fonte: Santa soja, de 1979. 
Figura 7 - Fotografia de Jacqueline Joner

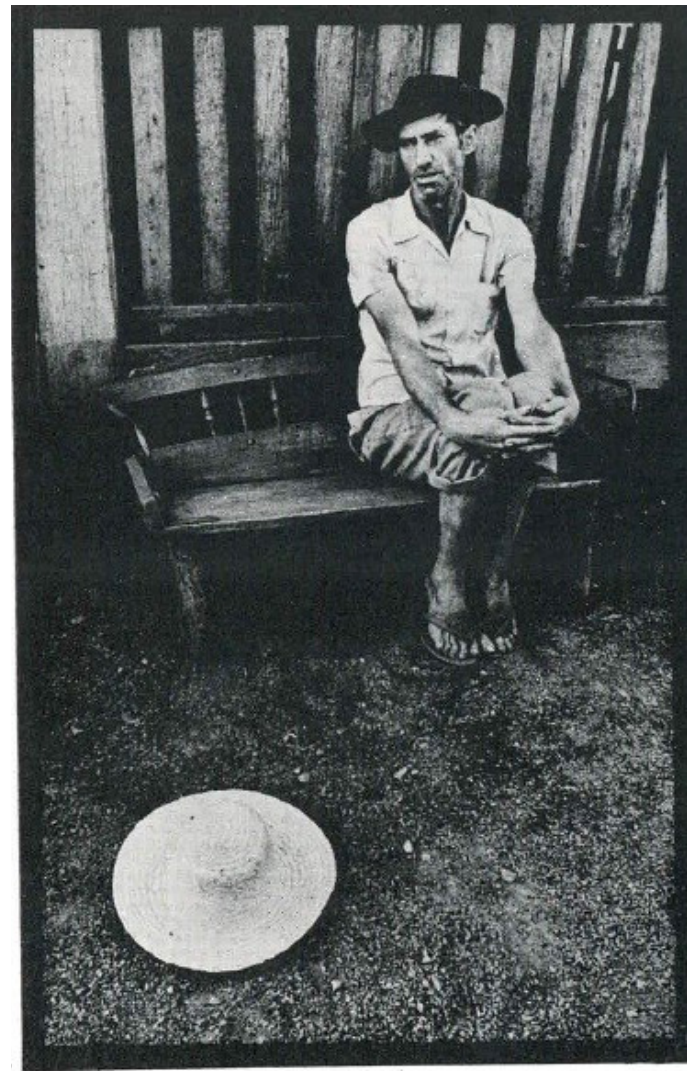

Fonte: Santa soja, de 1979.

Figura 8 - Fotografia de Eneida Serrano

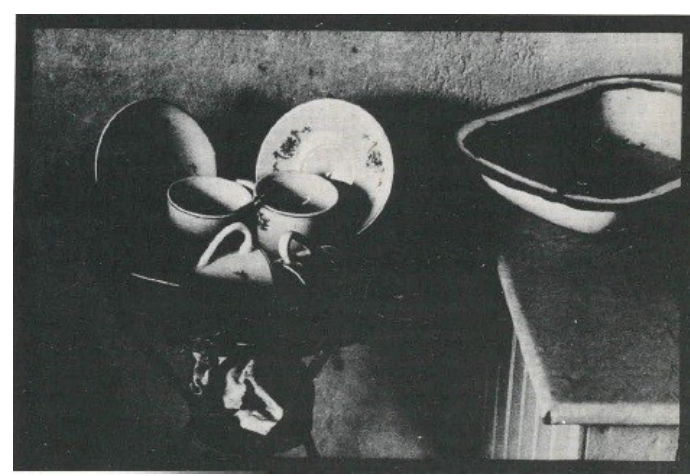

Fonte: Santa soja, de 1979.

\section{À guisa de conclusão}

Pretendemos mostrar um pouco do início da trajetória de trabalho das fotógrafas gaúchas Jacqueline Joner e Eneida Serrano, em fins dos anos 1970. É nesse momento que elas forjam alternativas para sua inserção no campo fotojornalístico gaúcho, ${ }^{14}$ diante das dificuldades encontradas por serem mulheres e terem formação superior. Procuramos analisar esse momento a partir da perspectiva feminista materialista, pela qual as relações sociais e de gênero geram não só situações de dominação, opressão e exploração, mas também formas de resistência. Assim, entendemos que a própria escolha profissional (fotojornalismo) já é, em si, uma forma de resistência, na medida em que não era uma escolha recorrente para as mulheres. As outras formas são a participação em cooperativas de jornalistas e fotógrafos (como a Coojornal e a Ponto de Vista) e a publicação do livro Santa soja, que possibilitaram a consolidação dessas profissionais no mercado de trabalho. Muito há ainda a ser pesquisado sobre as mulheres na fotografia no Rio Grande do Sul, e esperamos que essa reflexão abra caminho para muitas outras, adensando a história da fotografia brasileira.

\section{Resumen}

Este artículo tiene por objetivo presentar y problematizar el trabajo de dos fotoperiodistas gaúchas durante la década de 1970, Jacqueline Joner (1953) y Eneida Serrano (1952), a fin de comprender su inserción y papel en el campo foto-periodístico gaúcho. Las fotógrafas forman 
parte de la historia de la fotografía brasileña, permitiéndonos comprender las tensiones en las relaciones de trabajo y las formas de opresión que sufrieron, pero también sus mecanismos de emancipación. Así, abordaremos, de modo específico, las fotografías del foto libre Santa soja, el paso por el periódico Agricultura $\mathcal{E}$ Cooperativismo y la agencia de fotografía Ponto de Vista.

Palabras clave: Feminismo. Fotografía documental. Fotoperiodismo.

\section{Abstract}

This article aims to present and problematize the work of two south-Brazilian photojournalists in the 1970s, Jacqueline Joner (1953) and Eneida Serrano (1952), in order to understand their insertion and their role in the photojournalistic field. The photographers are part of the history of Brazilian photography, allowing us to understand the tensions in the work relations of women photographers, the forms of oppression they suffered, but also their mechanisms of emancipation. Thus, we will specifically address the photographs of the Santa soja photo book, the passage through the newspaper Agricultura \& Cooperativismo and the photography agency Ponto de Vista.

Keywords: Feminism. Documentar photography. Photojournalism.

\section{Notas}

1 O presente trabalho foi realizado com apoio da Coordenação de Aperfeiçoamento de Pessoal de Nível Superior (Capes), Código de Financiamento 001.

2 Sobre isso, ver Moreira (2012) e Ribeiro (2014).

3 Com elas trabalharam outras duas fotógrafas, Jussara Coelho e Lisete Guerra. Coelho também foi demitida na mesma época, e Guerra manteve o emprego por trabalhar como fotógrafa de moda (COLETIVA.NET, 2009).

4 Entrevista concedida a Charles Monteiro.

5 O jornal Correio do povo é do grupo Caldas Jr., como se refere a fotógrafa.

6 Fala de Jacqueline Joner na Semana da Fotografia, da Faculdade de Comunicação Social da PUCRS, em 05 de junho de 2017.

7 Sobre isso, ver o trabalho de Proença (2017) e Monteiro e Proença (2016). Uma das formas de valorização da profissão foi o crédito das fotografias. Na Agricultura \& Cooperativismo, em 1979, saía o nome dos fotógrafos e, entre parênteses, Agência Ponto de Vista.

8 Essa mudança de estatuto das imagens é tema para outro artigo, cuja pesquisa, ainda em desenvolvimento, busca identificar as fotografias presentes no fotolivro Santa soja que aparecem primeiro em fotorreportagens na revista Agricultura $\mathcal{E}$ Cooperativismo, procurando compreender os sentidos dessa mudança de uso das imagens.

9 Na época em que o livro foi preparado, Serrano estava morando em Londres, tendo deixado as fotografias pré-selecionadas com os colegas, o que explica o baixa quantidade de imagens.

10 A fotografia de Dorothea Lange foi feita dentro do projeto conhecido como Farm Security Administration, que, a partir de 1937, foi responsável por promover o desenvolvimento das regiões rurais dos EUA que padeciam dos efeitos da crise de 1929. Dentro desse escopo, havia um conjunto de fotógrafos, entre eles Lange e Walker Evans, responsáveis pela documentação das áreas rurais, gerando um número considerável de imagens reconhecidas atualmente por seu valor não apenas documental, mas também estético.

11 Essa fotografia atualmente faz parte da Coleção Pirelli Masp.

12 A série Interiores virou exposição em 2007, na galeria Bolsa de Arte, e ganhou o Prêmio Açoriano de Exposição no mesmo ano. Suas fotografias podem ser vistas em: <http://enciclopedia.itaucultural.org.br/pessoa21890/eneida-serrano > e <http://www.eneidaserrano.com.br/2010/index.html>. 
13 Sobre prática fotográfica, ver Canabarro (2005).

14 É importante mencionarmos que as autoras seguiram trabalhando como fotojornalistas para meios de comunicação nacionais importantes, como as revistas Veja e Isto É.

\section{Referências}

CANABARRO, Ivo. Fotografia, história e cultura fotografia: aproximações. Estudos Ibero-Americanos. PUCRS, Porto Alegre, v. 23, n. 2, p. 23-39, dez. 2005.

COLETIVA.NET. Jacqueline Joner: paixão pelo preto e branco. 20 mar. 2009. Disponível em: <https://coletiva.net/perfil/jacqueline-joner-paixao-pelo-preto-e-branco,164588.jhtml>. Acesso em: 12 maio 2018.

GUIMARÃES, Nadya Araujo; BRITO, Murillo Marschner Alves de. Mercantilização no feminino: a visibilidade do trabalho das mulheres no Brasil. In: ABREU, Alice Rangel de Paiva; HIRATA, Helena; LOMBARDI, Maria Rosa (Org.). Gênero e trabalho no Brasil e na França: perspectivas interseccionais. São Paulo: Boitempo, 2016. p. 63-85.

KERGOAT, Danièle. O cuidado e a imbricação das relações sociais. In: ABREU, Alice Rangel de Paiva; HIRATA, Helena; LOMBARDI, Maria Rosa (Org.). Gênero e trabalho no Brasil e na França: perspectivas interseccionais. São Paulo: Boitempo, 2016. p. 97-113.

KUCINSKI, Bernardo. Jornalistas e revolucionários: nos tempos da imprensa alternativa. São Paulo: Página Aberta, 1991.

MAUAD, Ana Maria. O olhar engajado: fotografia contemporânea e as dimensões políticas da cultura visual. ArtCultura, Uberlândia, v. 10, n. 16, p. 33-50, jan./jun. 2008.

MONTEIRO, Charles; PROENÇA, Caio. O fotojornalismo em revista: o trabalho do fotógrafo e do editor de fotografia em Veja (1977). Revista Maracanan, Rio de Janeiro, v. 12, n. 14, p. 190-209, jan./jun. 2016.
MONTEIRO, Charles. História e fotojornalismo: reflexões sobre o conceito e a pesquisa na área. Revista Tempo e Argumento, Florianópolis, v. 8, n. 17, p. 64-89, jan./abr. 2016.

MOREIRA, Marina Rago. Alice Brill, retratos de uma metrópole. Primeiros escritos, São Paulo, n. 18, p. 2-35, jun. 2012.

PROENÇA, Caio. Confrontando visualidades no fotojornalismo de Veja $e$ Isto É: práticas fotográficas e fotorreportagens na segunda metade dos anos 1970. 2017. Dissertação (Mestrado em História) - Escola de Humanidades, Pontifícia Universidade Católica do Rio Grande do Sul, Porto Alegre, 2017.

RIBEIRO, Carmem Adriane. A produção fotográfica de Frieda D. Klos em Panambi-RS nas décadas de 1930-1940. In: RAMOS, Eloisa Helena Capovilla da Luz; ARENDT, Isabel Cristina; WITT, Marcos Antônio (Org.). Festas, comemorações e rememorações na imigração. São Leopoldo: Oikos, 2014. p. 1178-1191.

ROUILLÉ, André. A fotografia: entre documento e arte contemporânea. São Paulo: Senac, 2009.

SEIDL, Eduardo. Santa soja: narrativa documental em fotolivro. 2016. 193 f. Dissertação (Mestrado em Comunicação) - Ciências da Comunicação, Universidade do Vale dos Sinos, São Leopoldo, 2016.

ZERWES, Erika. A fotografia humanista e a construção de uma historiografia sobre a fotografia latino-americana. História: debates e tendências, Passo Fundo, v. 16, n. 2, p. 314-327, jul./dez. 2016. 